\title{
Association of opioid fills with centers for disease control and prevention opioid guidelines and payer coverage policies: physician, insurance and geographic factors
}

\author{
Adeniyi T. Togun ${ }^{1}\left[\right.$ Pinar Karaca Mandic ${ }^{2} \cdot$ Rebecca Wurtz $^{3} \cdot$ Molly Moore Jeffery $^{4} \cdot$ Timothy Beebe $^{3}$
}

Received: 16 September 2021 / Accepted: 21 November 2021 / Published online: 2 December 2021

(c) The Author(s), under exclusive licence to Springer Nature Switzerland AG 2021

\begin{abstract}
Background The Centers for Disease Control and Prevention (CDC) issued guidelines and certain healthcare payers have made pharmacy coverage changes (PCC) focusing on regulating prescription opioids. Aim We evaluated differences in the rate of first-time opioid fills at doses $\geq 50$ morphine milligram equivalents (MME)/day and first-time opioid fills with benzodiazepine fill overlap following the CDC guidelines and following a PCC between provider types, geographic locations, and insurance types. Method We used OptumLabs® Data Warehouse claims data between 2014 and 2018. Subjects were opioid naïve non-cancer care patients, 18 years and older who had an identified chronic pain condition ICD diagnosis within 2 weeks prior to their first-time opioid fill. We used multiple treatment period segmented regression analysis with interaction terms to test the differences between primary care providers (PCPs) and specialist providers (SPs), urban and rural primary care service areas (PCSAs), and Medicare Advantage (MA) and commercially insured patients (CIPs) in their first-time opioid fill patterns. Results Prescribing first-time opioid fills at doses $\geq 50 \mathrm{MME} /$ day declined following the CDC guidelines and PCC, the decline was greater among SPs than PCPs and in rural PCSAs than urban PCSAs. Also, following the CDC guidelines, the decline was greater among MA patients however following the PCC the decline was greater among CIPs. There were no differences in rate of first-time opioid fill with benzodiazepine overlap between groups. Conclusion Responses to the CDC opioid guidelines and a PCC differed between PCPs and SPs, urban and rural PCSAs, and when prescribing to MA and CIPs. Understanding these differences is important to help inform future guidelines.
\end{abstract}

Keywords CDC opioid guidelines $\cdot$ Insurance type and geography $\cdot$ Opioids $\cdot$ Payer coverage change $\cdot$ Provider specialty

\section{Impacts on practice}

Adeniyi T. Togun

niyitogun@gmail.com

1 Division of Health Services Research, Policy \& Administration, School of Public Health, University of Minnesota Twin Cities, Minneapolis, US

2 OptumLabs® Visiting Fellow, Minneapolis, US

3 Division of Health Policy and Management, School of Public Health, University of Minnesota Twin Cities, Minneapolis, US

4 Department of Health Services Research, Mayo Clinic, Rochester, US
- Response to the CDC guidelines and payer coverage change with first-time opioid fills at doses $\geq 50 \mathrm{MME}$ per day differed based on provider specialty, patient insurance type and geography. Specialist providers also adopted the CDC guidelines and had a larger decline in rate of first-time opioid fills at doses $\geq 50 \mathrm{MME}$ per day than primary care providers following the guidelines.

- Also, following the payer coverage change, decline in rate of first-time opioid fills at doses $\geq 50 \mathrm{MME}$ per day was larger in rural PCSAs than urban PCSAs and among commercially insured patients than among the Medicare Advantage patients.

- Understanding these differences is crucial to better refine current guidelines and inform future guidelines and payer coverage change targets. 
- Health payers could be incentivized to create additional policies addressing first-time opioid prescribing at doses $\geq 50 \mathrm{MME}$ per day especially in commercially insured patients, because they have a higher level of firsttime opioid prescriptions at doses $\geq 50 \mathrm{MME}$ per day than Medicare Advantage patients.

- Commercial health payers can provide more guidance and strategies on opioid initiation practices as CMS is doing for Medicare patients.

\section{Introduction}

Drug overdose is a leading cause of death among people under 50 years in the US [1], and during the current Covid-19 pandemic, overdose deaths have spiked even further [2]. In 2016, drug overdose resulted in 63,632 deaths, $66 \%$ of which involved prescription and illicit opioids (such as heroin and fentanyl) overdose [3]. Following the onset of the Covid-19 pandemic in the US in March 2020, there has been a further spike in drug overdose deaths and 92,476 drug overdose deaths were reported in 2020 [4], with over $60 \%$ of the deaths attributed to synthetic opioids [5]. Increase in prescription opioid distribution has been linked with a rise in opioid related deaths [6]. During 2016, greater than $40 \%$ of all US opioid overdose deaths involved a prescription opioid [7]. Prescription opioid related overdose deaths were also on the rise and increased by $10.6 \%$ between 2015 and 2016 [8]. Primary care (PC) providers and specialists all prescribe opioids, however PC providers account for about $50 \%$ of prescribed opioids dispensed $[9,10]$, and family medicine and internal medicine providers compared to other specialties, are associated with the greatest number of prescription opioid fatalities [11]. Hence, the Centers for disease control and prevention (CDC) in March 2016 released opioid prescription guidelines for chronic pain to PC providers [12] in a bid to reduce the risk associated with opioid prescribing. However, because clinicians often adopt evidencebased recommendations from outside of their own areas of practice [13-16], specialist providers also adopted the CDC guideline [17]. Hence, this study evaluates differences in response to two CDC guideline recommendations on first-time opioid fill patterns between PC and specialist providers. Also, since patient health plans are known to affect physician prescribing habits $[18,19]$, we also evaluate how changes in first-time opioid fills following the CDC guideline differ between commercially insured patients compared to Medicare Advantage (MA) patients. MA is a Medicare-approved plan from a private company that offers an alternative to traditional fee-forservice Medicare (a public health insurance program in the United States that primarily provides health insurance for persons aged 65 and older) [20] while commercial health insurance is a private health insurance plan typically for persons younger than 65 and is not administered by the government. $67 \%$ of Americans have commercial insurance, and $55 \%$ of private insurance is employer sponsored [21]. Lastly, the opioid overdose death rate is higher in rural areas than urban areas $[22,23]$. However, evidence is scarce regarding whether uptake of the CDC guidelines aimed at reducing overdose deaths differs between rural and urban areas. Primary care service areas (PCSA) are the smallest geographic area that have been mapped out such that most of the of patients living in these areas use primary care services form within the area. Hence, we also evaluate how responses to the CDC guidelines differ between rural and urban PCSAs.

- $C D C$ Guideline 5 "When opioids are started, clinicians should prescribe the lowest effective dosage. Clinicians should use caution when prescribing opioids at any dosage, should carefully reassess evidence of individual benefits and risks when considering increasing dosage to $\geq 50$ morphine milligram equivalents (MME)/day, and should avoid increasing dosage to $\geq 90 \mathrm{MME} /$ day or carefully justify a decision to titrate dosage to $\geq 90 \mathrm{MME} /$ day" [12].

- $C D C$ Guideline 8 "Clinicians should avoid prescribing opioid pain medication and benzodiazepines concurrently whenever possible" [12].

Guideline 5 discouraging starting opioid prescriptions at doses $\geq 50$ morphine milligram equivalents (MME) per day aims to mitigate opioid complications which increase at higher doses such as overdose and death [24, 25]. Guideline 8 discouraging starting opioid prescription overlapping with benzodiazepines is crucial since both benzodiazepines and opioids cause respiratory suppression, and when taken together, increases the likelihood of overdose deaths [24]. Studies have shown that the CDC guidelines were associated with reduction in opioid prescription at doses $\geq 50 \mathrm{MME}$ per day and opioid fills with benzodiazepine overlap [26, 27], however it is unknown whether these reductions differed between prescribing provider types, patient insurance types and location in urban or rural primary care service areas (PCSAs).

Some US healthcare payers also implemented payer coverage changes to help reinforce the CDC guidelines. For example, a healthcare payer implemented the following coverage change: on the 1st of March 2018, members new to opioid therapy (no use in the last 120 days) were limited to a maximum dosage of 49 MME per day [28]. Higher doses ( $\geq 50$ MME per day) will still covered for certain circumstances such as pain due to sickle cell crisis [28]. It is unknown whether the changes following this payer 
coverage change differ between prescribing provider type, patient insurance type and location in urban or rural primary care service areas (PCSAs).

\section{Aim}

Firstly, the study evaluates if the changes in first-time opioid fills at doses $\geq 50 \mathrm{MME}$ per day associated with introduction of the CDC guidelines and payer pharmacy coverage change differed between PC providers and specialist providers (see Table 1 for provider specialty classification), Medicare Advantage (MA) and commercially insured patients, and between urban and rural PCSAs.
Secondly, the study evaluates if the changes in first-time opioid fills with benzodiazepine overlap associated with introduction of the CDC guidelines differed between PC providers and specialist providers, MA and commercially insured patients, and between urban and rural PCSAs. For the second aim we only evaluate differences following the CDC guidelines since there was no payer coverage change discouraging opioid fills with benzodiazepine overlap.

\section{Ethics approval}

This study was considered IRB exempt by the University of Minnesota Institutional Review Board (IRB ID:

Table 1 Patient and provider characteristics on first-time opioid fill

\begin{tabular}{|c|c|}
\hline & $\mathrm{N}(\%) /$ Mean $(\mathrm{SD})$ \\
\hline AGE & $57.68(16.52)$ \\
\hline MEAN NUMBER OF COMORBIDITIES (ELIXHAUSER) & $1.79(1.96)$ \\
\hline \multicolumn{2}{|l|}{ SEX } \\
\hline Female & $314,603(57.1)$ \\
\hline Male & $236,366(42.9)$ \\
\hline \multicolumn{2}{|l|}{ INSURANCE TYPE } \\
\hline Commercial & $325,948(59.2)$ \\
\hline MA & $225,021(40.8)$ \\
\hline \multicolumn{2}{|l|}{ PCSA } \\
\hline Urban & $457,934(83.1)$ \\
\hline Rural & $93,035(16.9)$ \\
\hline \multicolumn{2}{|l|}{ CENSUS REGIONS } \\
\hline South & $259,786(47.1)$ \\
\hline Midwest & $157,502(28.6)$ \\
\hline West & $77,191(14.0)$ \\
\hline Northeast and others & $56,490(10.3)$ \\
\hline \multicolumn{2}{|l|}{ ALL FIRST-TIME OPIOID FILLS ACROSS PROVIDER SPECIALTIES } \\
\hline PRIMARY CARE PROVIDER TYPE & $160,447(29.1)$ \\
\hline Family practice specialty & $99,091(17.9)$ \\
\hline Internal medicine specialty & $55,507(10.1)$ \\
\hline $\mathrm{OB} / \mathrm{GYN}$ and Pediatrics specialty & $5,849(1.1)$ \\
\hline SPECIALIST PROVIDER TYPE & $233,308(42.4)$ \\
\hline Emergency medicine specialty & $47,729(8.7)$ \\
\hline Internal medicine subspecialist & $14,937(2.7)$ \\
\hline \multicolumn{2}{|l|}{$\begin{array}{l}\text { Cardiologist, pulmonologist, neurologist, critical care medicine, gastroenterologist, dermatologist, nephrologist, } \\
\text { hematologist, geriatrician, rheumatologist, endocrinologist, immunologist, allergist, addiction medicine and infectious } \\
\text { disease specialist }\end{array}$} \\
\hline \multicolumn{2}{|l|}{ Surgeon specialty } \\
\hline $\begin{array}{l}\text { Thoracic surgeon, colon and rectal surgeon, neurosurgeon, urologist, orthopedic surgeon, oncologist, plastic surgeon, } \\
\text { vascular surgeon, general surgeon, hand surgeon and otolaryngologist surgeon }\end{array}$ & $148,205(26.9)$ \\
\hline \multicolumn{2}{|l|}{ Other specialists } \\
\hline $\begin{array}{l}\text { Radiologist, rehabilitation medicine, nuclear medicine, neuropathologist, pathologist, ophthalmologist, podiatrist MD } \\
\text { and psychiatrist }\end{array}$ & $22,437(4.1)$ \\
\hline \multicolumn{2}{|l|}{ OTHER/UNKNOWN PROVIDER TYPE } \\
\hline Other, unknown specialty & $157,214(28.5)$ \\
\hline
\end{tabular}

PCSA, Primary Care Service Areas; OB, Obstetrics; GYN, Gynecology 
STUDY00012681) on $4 / 6 / 2021$, because the data was existing and deidentified.

\section{Method}

\section{Study population}

First-time opioid fills for patients were identified between January 1, 2014 and December 31, 2018 from OptumLabs ${ }^{\circledR}$ Data Warehouse (OLDW) [29] claims database, a nationwide claims database of de-identified administrative medical and pharmacy claims for commercial and MA enrollees containing information on over 100 million enrollees [30]. The database contains longitudinal health information on enrollees and patients, representing a mix of ages, ethnicities, and geographical regions across the United States. Study subjects were required to have 6 months of continuous enrollment with medical and pharmacy coverage prior to their first-time opioid fill—baseline period. The study subjects were also required to be opioid naïve in the baseline period (have no prior opioid fill in the prior 6 months to their current first-time opioid fill). Fills of all first-time opioid doses including tramadol (but excluding buprenorphine and methadone, opioids frequently used to treat opioid addiction) were captured in the study period. Patients with any cancer diagnosis codes or hospice care codes (see appendix (ESM)) in the baseline period were excluded. Patients were required to be 18 years or older and have an identified chronic pain condition ICD (International Classification of Diseases) diagnosis identified via literature review [31-58] and boardcertified physician recommendations (see appendix (ESM)) within 2 weeks prior to first-time opioid fill.

\section{Outcome variables}

The unit of observation was the first opioid fill per patient in the study period. We had two study outcomes: (1) first-time opioid fills with a starting daily dose $\geq 50 \mathrm{MME}$ per day, calculated using the CDC formula "MME per day = strength per unit $\mathrm{x}$ (Number of units/days' supply) x MME conversion factor" $[25,59]$, and (2) first-time opioid fills with benzodiazepine [60] overlap, indicating when patients had a concurrent benzodiazepine fill days' supply overlapping with their first-time opioid fill day. Outcomes following the CDC guidelines and/or pharmacy coverage changes were evaluated to see if they differed between PC providers and specialist providers, commercially insured and MA patients, and rural and urban PCSAs.

Because the payer coverage change restrict first-time opioid coverage at doses $\geq 50$ MME per day, patients may have either opted to pay out of pocket to get higher doses or providers may have reduced their first-time opioid fill doses to just under 50 MME per day to get covered. Hence, we inspected the dosage distribution of first-time opioid fills before and after the payer policy change to verify whether after the payer coverage change, the first-time opioid fills $\geq 50 \mathrm{MME}$ per day were reduced to just under $50 \mathrm{MME}$ per day (40 to $49 \mathrm{MME} /$ day) just so they could be covered.

\section{Exposure measures}

The primary exposure variables were $\mathrm{CDC}$ guideline release and a payer coverage change. Other covariates included patient age in years at the time of first-time opioid fill, sex, patient insurance type (commercial or MA), residence in an urban or rural primary care service area (PCSA), and number of Elixhauser comorbidities [61] in the baseline period. Each of the Elixhauser comorbidities are flagged as an indicator variable in the baseline and the total number of Elixhauser comorbidities in the baseline are counted per patient and treated as a continuous variable in the models.

Primary care service areas (PCSAs) are standardized systems of known geographical units that measure access to primary care resources, utilization, supply and associated outcomes [62]. Patients were assigned to PCSAs using their zip codes according to the Dartmouth Atlas [63]. A single PCSA is made up of several census tracts. The populationweighted proportion of census tracts that were classified with a USDA rural-urban commuting area (RUCA) codes of 3 or lower [64] was calculated. If the weighted proportion was greater than or equal to 0.75 , that PCSA was considered to be metropolitan or urban and if less than 0.75 , the PCSA was considered to be non-metropolitan or rural.

\section{Statistical analysis}

We used a segmented regression discontinuity linear probability model with interaction terms to test the difference in immediate change in level and monthly change in rate over time in fill of first-time opioid at doses $\geq 50 \mathrm{MME} /$ day before and after the CDC guidelines and before and after the payer coverage change between groups (Fig. 1). Similarly, a segmented regression discontinuity linear probability model with interaction terms was used to test the difference in immediate change in level and monthly change in rate over time in fill of first-time opioid fill with benzodiazepine overlap before and after the CDC guidelines between groups. We chose a linear probability model over a logit model to produce readily interpretable estimates and show the difference between groups in how much the fill patterns change after release of the CDC guidelines and a payer coverage change [65-67]. The groups compared are as follows: PC providers and specialist providers, prescribing to commercially insured and MA patients; and patients receiving care in urban and rural PCSAs. 


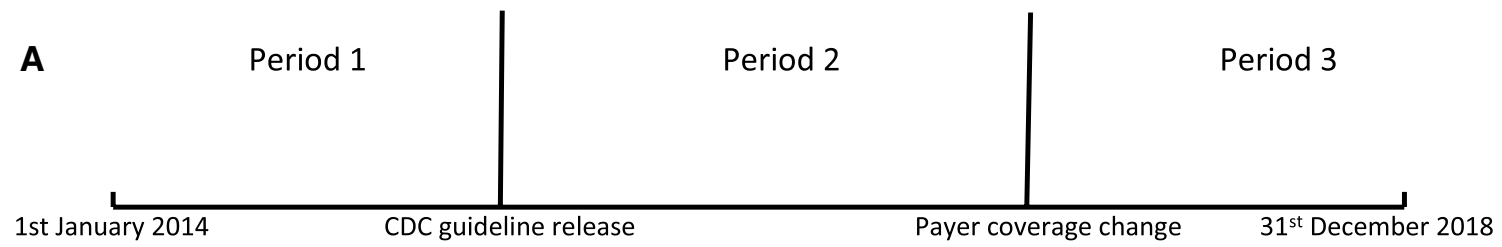

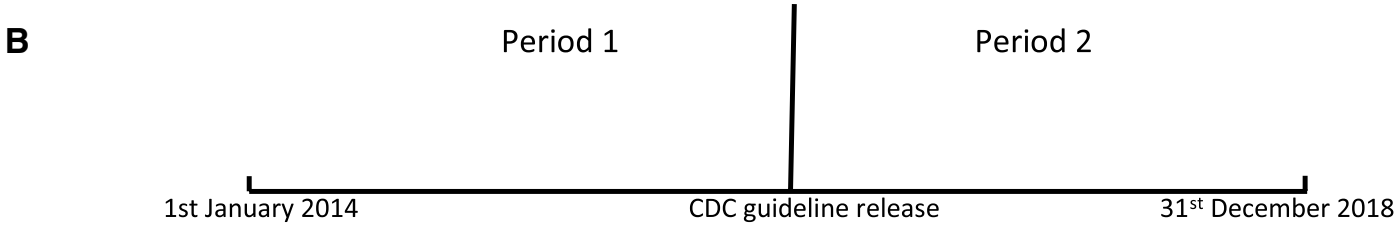

Fig. 1 Three Time Period Diagram for First-time Opioid Dose $\geq 50 \mathrm{MME} /$ day and Two Time Period Diagram for Firsttime Opioid Fill Overlap with Benzodiazepine. Key: CDC guideline release $=$ March 15, 2016, pharmacy coverage change $=$ March 1, 2018, figure A represents the timeline for first-time opioid

All models controlled for age, sex and number of Elixhauser comorbidities in the baseline. All analyses were performed using DbVisualizer version 10.0.15 [68] and Stata 14 [69].

\section{Results}

As shown in Table 1, the study sample comprised of 550,969 subjects of which $57.10 \%$ were female. Mean age was 57.68 (SD 16.52); 59.16\% were commercially insured (others had insurance through the MA program); and $83.11 \%$ lived in urban PCSAs. The mean number of Elixhauser comorbidities per patient prior to first-time opioid prescription was 1.79 (SD 1.96). Of all first opioid prescription fills during the study period $14.13 \%$ had doses $\geq 50 \mathrm{MME}$ per day, and $6.39 \%$ overlapped with a benzodiazepine fill.

Figure 2 shows the dosage distribution of first-time opioid fills before and after the payer policy change and verifies that indeed after the payer coverage change, the first-time opioid fills $\geq 50 \mathrm{MME}$ per day were reduced to just under 50MME per day (40 to 49MME/day) so they could be covered.

\section{Differences in response between primary care and specialist providers}

Table 2 shows the difference between PC versus specialist providers associated changes in first-time opioid fill at doses $\geq 50 \mathrm{MME}$ per day and first-time opioid fill with benzodiazepine overlap following the $\mathrm{CDC}$ guideline release and payer coverage change. dose $\geq 50 \mathrm{MME} /$ day and figure B represents the timeline for first-time opioid fill overlap with benzodiazepine. The interrupts were the exact months of the issuance of the CDC guideline and the payer coverage change

Following the CDC guideline release, we found no difference in the immediate change in level of first-time opioid fill at doses $\geq 50 \mathrm{MME}$ per day between PC and specialist providers, however, specialist providers had a stronger decline in the rate of associated fills (change in trend) than PC providers by 16.55 in every 10,000 fills (CI 8.39 to 24.71, $P<0.001)$. After the payer coverage change in March 2018, specialist providers had a larger immediate decline in level of first-time opioid fills at doses $\geq 50 \mathrm{MME}$ per day by 846 per 10,000 (CI 722.65 to $969.95, P<0.001$ ) than PC providers. Following the payer coverage change, specialist providers also had a stronger decline in the rate of associated fills (change in trend) by 93.86 per 10,000 fills (CI 78.90 to 109.42, $P<0.001)$ than PC providers.

With regards to first-time opioid fill with benzodiazepine overlap, following the CDC guideline release, we found no difference in the immediate change in level or change in rate of fills (change in trend) between PC and specialist providers.

\section{Differences in response between commercially insured and medicare advantage patients}

Table 3 shows the difference in associated changes in firsttime opioid fill at doses $\geq 50 \mathrm{MME}$ per day and first-time opioid fill with benzodiazepine overlap following the CDC guideline release and payer coverage change when prescribing to MA compared with commercially insured patients.

Following the CDC guideline release, we found no difference in the immediate decline in level and decline in rate of prescribing (change in trend) of first-time opioid fills at doses $\geq 50 \mathrm{MME}$ per day between MA patients compared to commercially insured patients. However, 
Table 2 Differences in response to CDC guidelines and payer coverage changes in prescribing first-time opioid dose $\geq 50 \mathrm{MME}$ per day and firsttime opioid with benzodiazepine overlap between primary care and specialist providers

First-time opioid dose $\geq 50 \mathrm{MME}$ per First-time opioid fill with benzodiazepine 10,000 Fills $(\mathrm{n}=393,755)[P][\mathrm{CI}] \quad$ overlap per 10,000 Fills $(\mathrm{n}=393,755)[P]$ $[\mathrm{CI}]$

Specialists pre-CDC guideline slope

Primary care minus specialists pre-CDC guideline slope

Specialists immediate change post-CDC guideline

Primary care minus specialist immediate change post-CDC guideline

Specialist post-CDC guideline change in slope

Primary care minus specialist post-CDC guideline change in slope

Specialists immediate change post-payer coverage change

Primary care minus specialists immediate change post-payer coverage change

Specialist payer coverage change in slope

Primary care minus specialist payer coverage change in slope

Constant

$\begin{array}{ll}10.25[P<0.001] & -2.90[P=0.003] \\ {[6.75 \text { to } 13.74]} & {[-4.84 \text { to }-0.97]} \\ -15.49[P<0.001] & 0.99[P=0.515] \\ {[-19.80 \text { to }-11.19]} & {[-1.99 \text { to } 3.97]} \\ -94.53[P=0.040] & -32.64[P=0.140] \\ {[-184.81 \text { to }-4.25]} & {[-75.96 \text { to } 10.68]} \\ 62.21[P=0.271] & 47.28[P=0.181] \\ {[-48.58 \text { to } 172.99]} & {[-22.06 \text { to } 116.61]} \\ -11.97[P<0.001] & -4.53[P<0.001] \\ {[-18.63 \text { to }-5.32]} & {[-6.73 \text { to }-2.33]} \\ 16.55[P<0.001] & -0.96[P=0.590] \\ {[8.39 \text { to } 24.71]} & {[-4.44 \text { to } 2.52]} \\ -943.81[P<0.001] & \\ {[-1046.18 \text { to }-841.44]} & \\ 846.30[P<0.001] & \\ {[722.65 \text { to } 969.95]} & \\ -121.78[P<0.001] & \\ {[-134.13 \text { to }-109.42]} & \\ 93.86[P<0.001] & \\ {[78.90 \text { to } 109.42]} & \\ 3442.722[P<0.001] & \\ {[3366.76 \text { to } 3518.68]} & \\ & \end{array}$

$P, P$ value; CI, 95\% Confidence Interval; CDC, Center for Disease Control and Prevention. Models adjusted for patient age, gender, number of Elixhauser comorbidities, insurance type (commercial insurance versus MA) and location in urban or rural primary care service area

Fig. 2 Opioid Dose Distribution Before and After the Payer Coverage Change Note: Pre-payer change period is after the CDC guideline release but before the payer coverage change (April 2016 - February 2018)

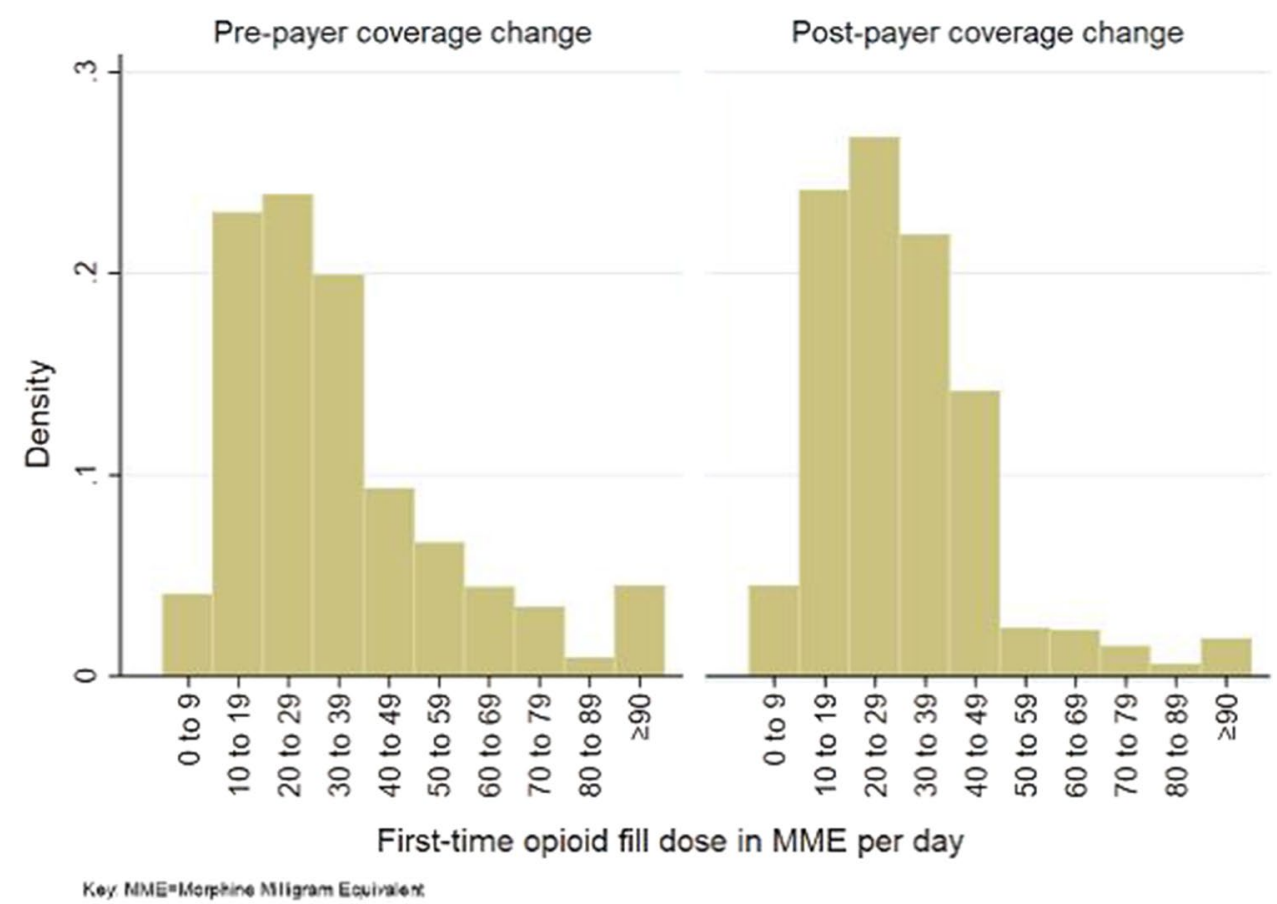


Table 3 Differences in response to the CDC guidelines and payer coverage changes in prescribing first-time opioid dose $\geq 50 \mathrm{MME}$ per day and first-time opioid with benzodiazepine overlap to MA versus commercially insured patients

First-time opioid > 50MME All prescrib- First-time opioid fill with benzodiazepine ers per 10,000 fills $(\mathrm{n}=550,969)[P][\mathrm{CI}] \quad$ overlap Per 10,000 fills $(\mathrm{n}=550,969)[P]$ $[\mathrm{CI}]$

\begin{tabular}{|c|c|c|}
\hline Commercially insured patients pre-CDC guideline slope & $\begin{array}{l}13.15[P<0.001] \\
{[10.51 \text { to } 15.78]}\end{array}$ & $\begin{array}{l}-1.68[P=0.032] \\
{[-3.22 \text { to }-0.14]}\end{array}$ \\
\hline $\begin{array}{l}\text { MA insured patients minus commercially insured patients } \\
\text { pre-CDC guideline slope }\end{array}$ & $\begin{array}{l}-5.45[P=0.008] \\
{[-9.44 \text { to }-1.45]}\end{array}$ & $\begin{array}{l}-0.13[P=0.926] \\
{[-2.92 \text { to } 2.68]}\end{array}$ \\
\hline $\begin{array}{l}\text { Commercially insured patients immediate change post- } \\
\text { CDC guideline }\end{array}$ & $\begin{array}{l}-058.10[P=0.118] \\
{[-130.87 \text { to } 14.67]}\end{array}$ & $\begin{array}{l}-26.86[P=0.146] \\
{[-63.08 \text { to } 9.35]}\end{array}$ \\
\hline $\begin{array}{l}\text { MA Insured patients minus commercially insured patients } \\
\text { immediate change post-CDC guideline }\end{array}$ & $\begin{array}{l}-54.51[P=0.440] \\
{[-156.40 \text { to } 47.37]}\end{array}$ & $\begin{array}{l}-11.69[P=0.711] \\
{[-72.74 \text { to } 49.60]}\end{array}$ \\
\hline $\begin{array}{l}\text { Commercially insured patients post-CDC guideline } \\
\text { change in slope }\end{array}$ & $\begin{array}{l}-7.69[P=0.007] \\
{[-13.16 \text { to }-2.21]}\end{array}$ & $\begin{array}{l}-5.59[P<0.001] \\
{[-7.41 \text { to }-3.77]}\end{array}$ \\
\hline $\begin{array}{l}\text { MA insured patients minus commercially insured patients } \\
\text { post-CDC guideline Change in slope }\end{array}$ & $\begin{array}{l}-4.26[P=0.070] \\
{[-11.71 \text { to } 3.19]}\end{array}$ & $\begin{array}{l}-1.08[P<0.495] \\
{[-7.41 \text { to } 3.77]}\end{array}$ \\
\hline $\begin{array}{l}\text { Commercially insured patients immediate change post- } \\
\text { payer coverage change }\end{array}$ & $\begin{array}{l}-1148.64[P<0.001] \\
{[-1239.12 \text { to }-1058.15]}\end{array}$ & \\
\hline $\begin{array}{l}\text { MA minus commercially insured patients immediate } \\
\text { change post-payer coverage change }\end{array}$ & $\begin{array}{l}1027.36[P<0.001] \\
{[913.88 \text { to } 1140.84]}\end{array}$ & \\
\hline $\begin{array}{l}\text { Commercially insured patients payer coverage change in } \\
\text { slope }\end{array}$ & $\begin{array}{l}-126.56[P<0.001] \\
{[-137.08 \text { to }-116.03]}\end{array}$ & \\
\hline $\begin{array}{l}\text { MA insured patients minus commercially insured patients } \\
\text { payer coverage change in slope }\end{array}$ & $\begin{array}{l}111.323[P<0.001] \\
{[97.60 \text { to } 125.04]}\end{array}$ & \\
\hline Constant & $\begin{array}{l}2561.01[P<0.001] \\
{[2500.30 \text { to } 2621.73]}\end{array}$ & $\begin{array}{l}926.321[P<0.001] \\
{[889.17 \text { to } 963.48]}\end{array}$ \\
\hline
\end{tabular}

$P, P$ value; CI, 95\% Confidence Interval; PCSA, Primary Care Service Area; CDC, Center for Disease Control and Prevention. Models adjusted for patient age, gender, number of Elixhauser comorbidities, insurance type (commercial insurance versus MA) and location in urban or rural primary care service area

following the payer coverage change there was a stronger immediate decline in level of prescribing first-time opioid fills at doses $\geq 50 \mathrm{MME}$ per day to commercially insured patients compared to MA patients by 1027.36 per 10,000 fills (CI 913.88 to $1140.84, P<0.001$ ). Following the payer coverage change, there was also a stronger decline in the rate of fill (change in trend) to commercially insured compared to MA patients by 111.32 per 10,000 fills (CI 97.60 to $125.04, P<0.001$ ).

With regards to first-time opioid fill with benzodiazepine overlap, following the CDC guideline release, we found no difference in the immediate change in level or change in rate of fills (change in trend) between commercially insured and MA patients.

\section{Differences in response between urban and rural PCSAs}

Table 4 shows the difference between urban PCSAs and rural PCSAs associated changes in first-time opioid fills at doses $\geq 50 \mathrm{MME}$ per day and first-time opioid fills with benzodiazepine overlap following the CDC guidelines and payer coverage change.

Following the CDC guideline release, we found no difference between the immediate change in level or change in rate (change in trend) of first-time opioid fills at doses $\geq 50 \mathrm{MME}$ per day between urban and rural PCSAs. However, following the payer coverage change, rural PCSAs had a larger immediate decline in level of firsttime opioid fills at doses $\geq 50 \mathrm{MME}$ per day than urban PCSAs by 199.98 per 10,000 fills (CI 63.05 to 336.91 , $P=0.004$ but there was no difference between rural and urban PCSAs in the rate of decline (change in trend). 
Table 4 Differences in response to the CDC guidelines and payer coverage changes prescribing first-time opioid dose $\geq 50 \mathrm{MME}$ per day and first-time opioid with benzodiazepine overlap between urban and rural PCSAs

First-time Opioid Dose Fill > 50MME First-time Opioid Fill with Benzodiazepine per 10,000 Fills $(\mathrm{n}=550,969)[P][\mathrm{CI}] \quad$ Overlap per 10,000 Fills $(\mathrm{n}=550,969)[P]$

$[\mathrm{CI}]$

\begin{tabular}{|c|c|c|}
\hline \multirow[t]{2}{*}{ Rural PCSA Pre-CDC guideline slope } & $11.65[P<0.001]$ & $-2.20[P=0.002]$ \\
\hline & [9.46 to 13.85$]$ & {$[-3.62$ to -0.79$]$} \\
\hline \multirow[t]{2}{*}{ Urban PCSA minus rural PCSA Pre-CDC guideline slope } & $-102.76[P=0.029]$ & $3.87[P=0.025]$ \\
\hline & {$[-12.08$ to -6.51$]$} & [.48 to 7.26$]$ \\
\hline \multirow[t]{2}{*}{ Rural PCSA immediate change post-CDC guideline } & $-102.76[P<0.001]$ & $-22.82[P=0.165]$ \\
\hline & {$[-160.17$ to -45.34$]$} & {$[-55.01$ to 9.36$]$} \\
\hline \multirow{2}{*}{$\begin{array}{l}\text { Urban PCSA minus rural PCSA immediate change post- } \\
\text { CDC guideline }\end{array}$} & $54.67[P=0.438]$ & $-49.68[P=0.191]$ \\
\hline & {$[-83.37$ to 192.72$]$} & {$[-124.14$ to 24.78$]$} \\
\hline \multirow[t]{2}{*}{ Rural PCSA post-CDC guideline change in slope } & $-10.93[P<0.001]$ & $-6.04[P<0.001]$ \\
\hline & {$[-15.13$ to -6.723$]$} & {$[-7.65$ to 4.44$]$} \\
\hline \multirow{2}{*}{$\begin{array}{l}\text { Urban PCSA minus rural PCSA post-CDC guideline } \\
\text { change in slope }\end{array}$} & $2.15[P=0.673]$ & $-2.27[P=0.232]$ \\
\hline & {$[-7.81$ to 12.10$]$} & {$[-6.00$ to 1.46$]$} \\
\hline \multirow{2}{*}{$\begin{array}{l}\text { Rural PCSA immediate change Post-Payer coverage } \\
\text { change }\end{array}$} & $-581.54[P<0.001]$ & \\
\hline & {$[-644.66$ to -518.41$]$} & \\
\hline \multirow{2}{*}{$\begin{array}{l}\text { Urban PCSA minus Rural PCSA immediate change post- } \\
\text { payer coverage change }\end{array}$} & $199.98[P=0.004]$ & \\
\hline & [63.05 to 336.91$]$ & \\
\hline \multirow[t]{2}{*}{ Rural PCSA payer coverage change in slope } & $-80.35[P<0.001]$ & \\
\hline & {$[-88.04$ to -72.65$]$} & \\
\hline \multirow{2}{*}{$\begin{array}{l}\text { Urban PCSA minus Rural PCSA payer coverage change } \\
\text { in slope }\end{array}$} & $16.02[P=0.060]$ & \\
\hline & {$[-0.66$ to 32.71$]$} & \\
\hline \multirow[t]{2}{*}{ Constant } & $2544.05[P<0.001]$ & $1057.44[P<0.001]$ \\
\hline & [2490.48 to 2597.62$]$ & [1023.31 to 1091.57$]$ \\
\hline
\end{tabular}

$P, P$ value; CI, 95\% Confidence Interval; PCSA, Primary Care Service Area; CDC, Center for Disease Control and Prevention. Models adjusted for patient age, gender, number of Elixhauser comorbidities, insurance type (commercial insurance versus MA) and location in urban or rural primary care service area

With regards to first-time opioid fills with benzodiazepine overlap, following the CDC guideline release, we found no difference in the immediate change in level or change in rate of fills (change in trend) between rural and urban PCSAs.

\section{Discussion}

The CDC guidelines currently focus on PC physicians because they account for about half of all prescribed opioids dispensed $[9,10]$. However, it is known that healthcare providers adopt knowledge from other specialties to improving clinical practice and patient safety [13-16]. Hence, specialist providers may have adopted the $\mathrm{CDC}$ guidelines in addition to the payer coverage change.

We found that compared with PC physicians, specialist providers appeared to have a larger reduction in firsttime opioid fills at doses $\geq 50 \mathrm{MME}$ per day following the CDC guidelines. Likewise, specialist providers appeared to have a larger reduction in first-time opioid fills at doses $\geq 50$ MME per days following payer coverage change than PC providers. This may stem from the fact that specialist providers had a higher rate of first-time opioid fills at doses $\geq 50 \mathrm{MME}$ per day prior to the CDC guideline release and payer coverage change, therefore these providers had more room for dose reduction than PC physicians.

Post-CDC guideline release, immediate decline in level or subsequent decline in rate of first-time opioid fills at doses $\geq 50 \mathrm{MME}$ per day did not differ between MA and commercially insured patients. However, following the payer coverage change, commercially insured patients had a larger decline in level and rate (change in trend) of first-time opioid fills at doses $\geq 50 \mathrm{MME}$ per day than MA patients. This may be due to the more comprehensive nature of the MA plans in lowering cost sharing and increasing access to medications, in contrast, commercially insured patients who are more bound by the payer coverage change. Further encouragement from Center for Medicare and Medicaid services (CMS) through release of additional technical guidance on strategies for reducing first-time opioid fill doses such as that in 2018 [70], may be beneficial in MA plans. 
Following both the CDC guidelines and pharmacy coverage change, there was no difference in immediate decline and change in rate (change in trend) of first-time opioids fill at doses $\geq 50 \mathrm{MME}$ per day between rural than urban PCSAs. However, following payer coverage change, there was a larger immediate decline in level of first-time opioids fill at doses $\geq 50 \mathrm{MME}$ per day in rural than urban PCSAs. This may also be because rural PCSAs had a higher rate of first-time opioid fills at doses $\geq 50 \mathrm{MME}$ per day prior to the pharmacy coverage changes, therefore they had more room for dose reduction than urban PCSAs. However, following the payer coverage change, the change in rate of decline (change in trend) of first-time opioid fills at dose $\geq 50 \mathrm{MME}$ per day did not differ between rural and urban PCSAs.

\section{Limitations}

Our results show an association rather than a causal effect of guidelines and payer/pharmacy coverage changes on provider prescribing behavior, and causality cannot be inferred from observational study designs. In the claims data, we observe only opioid fills, not all written prescriptions by providers, and the data may be missing fills for patients who pay out of pocket. Finally, our analysis evaluates at the national level and may not have accounted for some state level policies on opioid prescribing during the study period (For example, Nevada and Arizona limit opioid prescribing doses to 90 MMEs per day, Maine limits to $100 \mathrm{MME}$ per day, and Rhode Island limit to $50 \mathrm{MME}$ per day) [71]. Similarly, healthcare organizations may have specific policies we are not able to observe.

\section{Conclusion}

The study leveraged a large US claims database with a large sample size to show that response to the CDC guidelines and payer coverage change with first time opioid fills at doses $\geq 50 \mathrm{MME}$ per day differed between provider specialty. Understanding these differences is crucial to better refine current guidelines and inform future guidelines and payer coverage change targets. Likewise, factors that influence response to guidelines such as patient insurance types and location in urban or rural PCSAs should also be considered when developing future guidelines. Health payers could also be incentivized to create more policies addressing first-time opioid prescribing behavior, especially in commercially insured patients, because they have a higher level of being prescribed first-time opioids at doses $\geq 50 \mathrm{MME}$ per day. Commercial payers could provide more guidance and strategies on opioid initiation practices as CMS is doing for Medicare patients. Clinical pharmacists can also help counsel patients on recommended guidelines and opioid risks during opioid dispensing.

Supplementary Information The online version contains supplementary material available at https://doi.org/10.1007/s11096-021-01360-w.

Acknowledgements Jeannine Ouellette, MFA from the Minnesota Evidence-Based Practice Center is acknowledged for proofreading the manuscript. Dr. Itegbemie Obaitan (a gastroenterologist), Dr. Olusola Adegoke (a family physician) and coauthor-Dr Rebecca Wurtz (a family physician and associate professor) are acknowledged for their clinical input on validation and recommendation of chronic pain condition ICD codes used in the study. This research was funded by Agency for Healthcare Research and Quality (R01 HS025164) (PI: Karaca-Mandic)

Funding This research was funded by Agency for Healthcare Research and Quality (R01 HS025164) (PI: Karaca-Mandic). The funding agency had no involvement with the study design, analysis, writing or decision to submit this article for publication.

Conflicts of interest There are no conflict of interest to disclose.

\section{References}

1. Centers for Disease Control and Prevention. Underlying Cause of Death, 1999-2017 Request. https://wonder.cdc.gov/controller/ saved/D76/D15F907. Accessed 29 Oct 2020.

2. Centers for Disease Control and Prevention. Vital Statistics Rapid Release: Provisional Drug Overdose Data. Published September 8, 2020. https://www.cdc.gov/nchs/nvss/vsrr/drug-overdose-data. htm. Accessed 29 Oct 2020.

3. Scholl L, Seth P, Kariisa M, Wilson N, Baldwin G. Drug and opioid-involved overdose deaths-United States, 2013-2017. Morbidity and Mortality Weekly Report. 2019;67(51-52):1419.

4. Centers for Disease Control and Prevention. Provisional Drug Overdose Death Counts. https://www.cdc.gov/nchs/nvss/vsrr/ drug-overdose-data.htm. Accessed 29 Oct 2020.

5. Centers for Disease Control and Prevention. Provisional Drug Overdose Death Counts. https://www.cdc.gov/nchs/nvss/vsrr/ drug-overdose-data.htm Accessed 23 Oct 2021.

6. Baumgartner JC., Radley DC. "The Drug Overdose Mortality Toll in 2020 and Near-Term Actions for Addressing It," To the Point (blog), July 15, 2021, updated Aug. 16, 2021. https://doi.org/10. 26099/gb4y-r129. Accessed 23 Oct 2021.

7. U.S. Department of Health and Human Services. What is the U.S. Opioid Epidemic? HHS.gov. Published December 4, 2017. Accessed October 29, 2020. https://www.hhs.gov/opioids/aboutthe-epidemic/index.html. Accessed 29 Oct 2020.

8. Seth P. Overdose deaths involving opioids, cocaine, and psychostimulants - United States, 2015-2016. MMWR Morb Mortal Wkly Rep. 2018;67:349-58.

9. Centers for Disease Control and Prevention. Why Guidelines for Primary Care Providers? https://www.cdc.gov/drugoverdose/pdf/ guideline_infographic-a.pdf. Accessed 29 Oct 2020.

10. Gifford A, Quach C. Prescription of Opioid Medications in VA Outpatient Care. https://www.hsrd.research.va.gov/meetings/ 2001/HSRD2001AMab126.htm. Accessed 29 Oct 2020.

11. Porucznik CA, Johnson EM, Rolfs RT, et al. Specialty of prescribers associated with prescription opioid fatalities in Utah, 2002-2010. Pain Med Malden Mass. 2014;15(1):73-8. https:// doi.org/10.1111/pme.12247. 
12. Dowell D, Haegerich TM, Chou R. CDC guideline for prescribing opioids for chronic pain - United States, 2016. MMWR Recomm Rep Morb Mortal Wkly Rep Recomm Rep. 2016;65(1):1-49.

13. Bishop PB, Wing PC. Knowledge transfer in family physicians managing patients with acute low back pain: a prospective randomized control trial. Spine J Off J North Am Spine Soc. 2006;6(3):282-8. https://doi.org/10.1016/j.spinee.2005.10.008.

14. Dooks P. Diffusion of pain management research into nursing practice. Cancer Nurs. 2001;24(2):99-103. https://doi.org/10. 1097/00002820-200104000-00004.

15. Formoso G, Rizzini P, Bassi M, et al. Knowledge transfer: What drug information would specialist doctors need to support their clinical practice? Results of a survey and of three focus groups in Italy. BMC Med Inform Decis Mak. 2016. https://doi.org/10. 1186/s12911-016-0355-7.

16. Sanson-Fisher RW. Diffusion of innovation theory for clinical change. Med J Aust. 2004;180(S6):S55-6.

17. Togun AT, Karaca-Mandic P, Wurtz R, Jeffrey M, Beebe T. Association of $3 \mathrm{CDC}$ opioid prescription guidelines for chronic pain and 2 payer pharmacy coverage changes on opioid initiation practices. J Manag Care Spec Pharm. 2021;27(10):1352-64. https:// doi.org/10.18553/jmcp.2021.27.10.1352.

18. Joyce GF, Carrera MP, Goldman DP, et al. Physician prescribing behavior and its impact on patient-level outcomes. Am J Manag Care. 2011;17(12):e462-71.

19. Borenstein DG. Chronic low back pain. Rheum Dis Clin North Am. 1996;22(3):439-56. https://doi.org/10.1016/s0889-857x(05) 70281-7.

20. Centers for Medicare \& Medicaid Services. Medicare \& You. The Official U.S. Government Medicare Handbook. Published 2021. https://www.medicare.gov/Pubs/pdf/10050-medicare-and-you. pdf. Accessed 23 Oct 2021.

21. Tikkanen R, Osborn R, Mossialos E, et al. International health care system profiles United States. Published June 5, 2020. https:// www.commonwealthfund.org/international-health-policy-center/ countries/united-states Accessed 27 Oct 21.

22. Centers for Disease Control and Prevention. Opioid Overdoses Policy Brief. Published October 19, 2018. https://www.cdc.gov/ ruralhealth/drug-overdose/policybrief.html. Accessed 29 Oct 2020.

23. Hedegaard H, Miniño AM, Warner M. Urban-rural Differences in Drug Overdose Death Rates, by Sex, Age, and Type of Drugs Involved, 2017. NCHS data brief. 2019;(345):1-8.

24. Centers for Disease Control and Prevention. CDC Guideline for Prescribing Opioids for Chronic Pain. https://Stacks.Cdc.Gov/ View/Cdc/38277/Cdc_38277_DS1.Pdf. Accessed 29 Oct 2020.

25. Centers for Disease Control and Prevention. Calculating Total Daily Dose of Opioids for Safer Dosage. https://www.cdc.gov/ drugoverdose/pdf/calculating_total_daily_dose-a.pdf. Accessed 29 Oct 2020 .

26. Bohnert ASB, Guy GP, Losby JL. Opioid prescribing in the united states before and after the centers for disease control and prevention's 2016 opioid guideline. Ann Intern Med. 2018;169(6):36775. https://doi.org/10.7326/M18-1243.

27. Jeffery MM, Hooten WM, Jena AB, et al. Rates of physician coprescribing of opioids and benzodiazepines after the release of the centers for disease control and prevention guidelines in 2016. JAMA Netw Open. 2019;2(8):e198325. https://doi.org/10.1001/ jamanetworkopen.2019.8325.

28. United Healthcare. New strategies for fighting opioid misuse. https://www.uhc.com/employer/news/consultant/new-strategiesfor-fighting-opioid-misuse. Accessed 29 Oct 2020.

29. OptumLabs. OptumLabs and OptumLabs Data Warehouse (OLDW) Descriptions and Citation. 2019; OptumLabs Eden Prairie, MN
30. Grass F, Merchea A, Mathis KL, et al. Cost drivers of locally advanced rectal cancer treatment - an analysis of a leading healthcare insurer. J Surg Oncol. 2021;123(4):1023-9. https://doi.org/ 10.1002/jso.26390.

31. Farrar JT, Young JP, LaMoreaux L, et al. Clinical importance of changes in chronic pain intensity measured on an 11-point numerical pain rating scale. Pain. 2001;94(2):149-58. https://doi.org/10. 1016/s0304-3959(01)00349-9.

32. Treede R-D, Rief W, Barke A, et al. A classification of chronic pain for ICD-11. Pain. 2015;156(6):1003-7. https://doi.org/10. 1097/j.pain.0000000000000160.

33. Scholz J, Finnerup NB, Attal N, et al. The IASP classification of chronic pain for ICD-11: chronic neuropathic pain. Pain. 2019;160(1):53-9. https://doi.org/10.1097/j.pain.0000000000 001365.

34. Tompkins DA, Hobelmann JG, Compton P. Providing chronic pain management in the "fifth vital sign" Era: historical and treatment perspectives on a modern-day medical dilemma. Drug Alcohol Depend. 2017;173(Suppl 1):S11-21. https://doi.org/10.1016/j. drugalcdep.2016.12.002.

35. Stein SL. Chronic pelvic pain. Gastroenterol Clin North Am. 2013;42(4):785-800. https://doi.org/10.1016/j.gtc.2013.08.005.

36. van Hecke O, Torrance N, Smith BH. Chronic pain epidemiology and its clinical relevance. Br J Anaesth. 2013;111(1):13-8. https:// doi.org/10.1093/bja/aet123.

37. Fillingim RB, Bruehl S, Dworkin RH, et al. The ACTTIONAmerican pain society pain taxonomy (AAPT): an evidence-based and multidimensional approach to classifying chronic pain conditions. J Pain Off J Am Pain Soc. 2014;15(3):241-9. https://doi. org/10.1016/j.jpain.2014.01.004.

38. Schwartz ES, Gebhart GF. Visceral pain. Curr Top Behav Neurosci. 2014;20:171-97. https://doi.org/10.1007/7854_2014_315.

39. Addison RG. Chronic pain syndrome. Am J Med. 1984;77(3A):54-8. https://doi.org/10.1016/s0002-9343(84) 80102-3.

40. Borsook D. Neurological diseases and pain. Brain. 2012;135(2):320-44. https://doi.org/10.1093/brain/awr271.

41. Breivik H, Collett B, Ventafridda V, et al. Survey of chronic pain in Europe: prevalence, impact on daily life, and treatment. Eur J Pain Lond Engl. 2006;10(4):287-333. https://doi.org/10.1016/j. ejpain.2005.06.009.

42. Bryce TN, Biering-Sørensen F, Finnerup NB, et al. International spinal cord injury pain classification: part I Background description. Spinal Cord. 2012;50(6):413-7. https://doi.org/10.1038/sc. 2011.156.

43. Bryce TN, Biering-Sørensen F, Finnerup NB, et al. International spinal cord injury pain (ISCIP) classification: part 2. Initial Valid Vignettes Spinal Cord. 2012;50(6):404-12. https://doi.org/10. 1038/sc.2012.2.

44. Cervero F. Visceral pain--central sensitisation. Gut. 2000;47(90004):56-7. https://doi.org/10.1136/gut.47.suppl_4. iv56.

45. Diatchenko L, Nackley AG, Slade GD, et al. Idiopathic pain disorders-pathways of vulnerability. Pain. 2006;123(3):226-30. https:// doi.org/10.1016/j.pain.2006.04.015.

46. Diatchenko L, Slade GD, Nackley AG, et al. Genetic basis for individual variations in pain perception and the development of a chronic pain condition. Hum Mol Genet. 2005;14(1):135-43. https://doi.org/10.1093/hmg/ddi013.

47. Finnerup NB, Scholz J, Attal N, et al. Neuropathic pain needs systematic classification. Eur J Pain Lond Engl. 2013;17(7):953-6. https://doi.org/10.1002/j.1532-2149.2012.00282.x.

48. Fishman S, Ballantyne J, Rathmell JP. Bonica's Management of pain. Lippincott Williams \& Wilkins; 2010. 
49. Graven-Nielsen T, Wodehouse T, Langford RM, et al. Normalization of widespread hyperesthesia and facilitated spatial summation of deep-tissue pain in knee osteoarthritis patients after knee replacement. Arthritis Rheum. 2012;64(9):2907-16. https://doi. org/10.1002/art.34466.

50. Harden RN, Bruehl S, Perez RSGM, et al. Validation of proposed diagnostic criteria (the "Budapest Criteria") for complex regional pain syndrome. Pain. 2010;150(2):268-74. https://doi.org/10. 1016/j.pain.2010.04.030.

51. Hart OR, Uden RM, McMullan JE, et al. A study of national health service management of chronic osteoarthritis and low back pain. Prim Health Care Res Dev. 2015;16(2):157-66. https://doi. org/10.1017/S1463423614000140.

52. Jensen TS, Baron R, Haanpää M, et al. A new definition of neuropathic pain. Pain. 2011;152(10):2204-5. https://doi.org/10.1016/j. pain.2011.06.017.

53. Jensen MP, Chodroff MJ, Dworkin RH. The impact of neuropathic pain on health-related quality of life: review and implications. Neurology. 2007;68(15):1178-82. https://doi.org/10.1212/01.wnl. 0000259085.61898.9e.

54. Knowles CH, Aziz Q. Basic and clinical aspects of gastrointestinal pain. Pain. 2009;141(3):191-209. https://doi.org/10.1016/j.pain. 2008.12.011.

55. Kosek E, Ordeberg G. Abnormalities of somatosensory perception in patients with painful osteoarthritis normalize following successful treatment. Eur J Pain Lond Engl. 2000;4(3):229-38. https://doi.org/10.1053/eujp.2000.0175.

56. Kumar SP, Saha S. Mechanism-based classification of pain for physical therapy management in palliative care: a clinical commentary. Indian J Palliat Care. 2011;17(1):80-6. https://doi.org/ 10.4103/0973-1075.78458.

57. Sandroni P, Benrud-Larson LM, McClelland RL, et al. Complex regional pain syndrome type I: incidence and prevalence in Olmsted county, a population-based study. Pain. 2003;103(1-2):199207. https://doi.org/10.1016/s0304-3959(03)00065-4.

58. Juyia RF, Kerr HA. Return to play after liver and spleen trauma. Sports Health. 2014;6(3):239-45. https://doi.org/10.1177/19417 38114528468.

59. Centers for Disease Control and Prevention. CDC File of National Drug Codes for Selected Benzodiazepines, Muscle Relaxants, Stimulants, Opioid analgesics, and Linked Oral Morphine Milligram Equivalent Conversion Factors for Opioids, 2019 Version. Available upon request at https://centersfordiseasecontrol.share file.com/Authentication/Login. Accessed 2 Dec 2020.

60. NIH US National Library of Medicine. Benzodiazepines Drug Class. https://dailymed.nlm.nih.gov/dailymed/search.cfm?query=
Benzodiazepines $\&$ searchdb $=$ class \&labeltype $=$ all $\&$ sortby $=$ rel $\&$ audience $=$ professional $\&$ page $=1 \&$ pagesize $=200$. Accessed 23 Nov 2020.

61. Quan H, Sundararajan V, Halfon P, et al. Coding algorithms for defining comorbidities in ICD-9-CM and ICD-10 administrative data. Med Care. 2005;43(11):1130-9. https://doi.org/10.1097/01. mlr.0000182534.19832.83.

62. Goodman DC, Mick SS, Bott D, et al. Primary care service areas: a new tool for the evaluation of primary care services. Health Serv Res. 2003;38(1 Pt 1):287-309. https://doi.org/10.1111/1475-6773. 00116.

63. Wennberg JE, Cooper MM. The Dartmouth atlas of health care. The Center for the Evaluative Clinical Sciences: Dartmouth Medical School, American Hospital Publishing; 1996. pp. 15-20.

64. U.S. Department of Agriculture. Documentation: 2010 RuralUrban Commuting Area (RUCA) Codes. Published 2012. https:// www.ers.usda.gov/data-products/rural-urban-commuting-areacodes/documentation/. Accessed 29 Oct 2020.

65. Hellevik O. Linear versus logistic regression when the dependent variable is a dichotomy. Qual Quant. 2009;43(1):59-74. https:// doi.org/10.1007/s11135-007-9077-3.

66. Long JS, Long JS. Regression models for categorical and limited dependent variables. Sage; 1997 Jan 9.

67. Karaca-Mandic P, Norton EC, Dowd B. Interaction terms in nonlinear models. Health Serv Res. 2012;47(1 Pt 1):255-74. https:// doi.org/10.1111/j.1475-6773.2011.01314.x.

68. DbVisualizer. The Universal Database Tool For Developers, Analysts and DBAs. https://www.dbvis.com/. Accessed 29 Oct 2020.

69. Stata. Stata 14. https://www.stata.com/stata14/. Accessed 29 Oct 2020.

70. Ketcham M, Sexton G, Sparkman S et al. Medicare Part D Opioid Overutilization Strategies for 2019: Implementation of CARA and Other Policy Guidance. https://www.cms.gov/Medicare/Presc ription-Drug-Coverage/PrescriptionDrugCovContra/Downloads/ Medicare-Part-D-Spring-Conference-2018-CARA_Opioid-Confe rence-2018-CARA_Opioid-Presentation.pdf. Accessed 29 Oct 2020.

71. Liang Y, Turner B. Assessing risk for drug overdose in a national cohort: role for both daily and total opioid dose? J Pain. 2015;16(4):318-25.

Publisher's Note Springer Nature remains neutral with regard to jurisdictional claims in published maps and institutional affiliations. 